\title{
Development and implementation of a paediatric dosing calculator integrated in the Dutch Paediatric Formulary
}

\author{
Tjitske M. van der Zanden ${ }^{1,4,5} \cdot$ Lennard Goedknegt $^{6} \cdot{\text { Matthijs de } \text { Hoog }^{2} \cdot \text { Miriam G. Mooij }^{7} \cdot \text { Saskia N. de Wildt }}^{2,4,5}$. \\ I. Heleen van der Sijs ${ }^{3}$
}

Published online: 9 April 2020

(c) The Author(s) 2020

\begin{abstract}
Calculation errors are the most common dosing errors in paediatrics. While health information technology has been advocated to improve patient safety, the broad implementation of computer-calculated dosing in the paediatric setting is delayed for the lack of computable, explicit and unambiguous paediatric dosing guidelines. The structured digital dosing guidelines of the Dutch Paediatric Formulary permitted the development of a paediatric dosing calculator that combines drug dosing recommendations of the formulary with patient variables. We took into account the European Union Medical Devices Directive (EEC 93/43) and international standards describing the requirements for the development and maintenance of medical software, the risk management in relation to medical devices and the application of usability engineering to medical devices. As key steps in the development and risk management of software, we first specified the intended use and primary operating functions, then identified potential failures and resolved failures by corrective measures. The paediatric dosing calculator calculates an individual dose based on specified patient characteristics and the dose recommendations provided in the formulary. This is a step-by-step process where a user first enters patient variables (date of birth, weight) and then selects drug variables (indication, route of administration). Based on the selected patient and drug variables, an individual dose is calculated. In addition, the calculated dose in weight units (grams, milligrams) can be converted to a volume-based dose (millilitres) of a fluid product. We successfully developed and implemented a dosing calculator in our national web-based Dutch Paediatric Formulary, which so far has been used more than 65,000 times monthly.
\end{abstract}

Electronic supplementary material The online version of this article (https://doi.org/10.1007/s40267-020-00724-y) contains supplementary material, which is available to authorized users.

Tjitske M. van der Zanden

t.vanderzanden@erasmusmc.nl

1 Department of Paediatrics, Erasmus MC, Sophia Children's Hospital, Wytemaweg 80, 3015 CN Rotterdam, The Netherlands

2 Intensive Care and Department of Paediatric Surgery, Erasmus MC Sophia Children's Hospital, Rotterdam, The Netherlands

3 Department of Hospital Pharmacy, Erasmus MC, Rotterdam, The Netherlands

4 Department of Pharmacology and Toxicology, Radboud Institute for Health Sciences, Radboud University, Nijmegen, The Netherlands

5 Dutch Knowledge Center Pharmacotherapy for Children, Den Haag, The Netherlands

6 HealthESolutions, Rotterdam, The Netherlands

7 Department of Paediatrics, Leids Universitair Medisch Centrum, Leiden, The Netherlands

\section{Why do we need a paediatric dosing calculator?}

Incorrect dosing accounts for up to $34 \%$ of all potential adverse drug events in paediatric patients [1]. Among all dosing errors, calculation errors are the most common errors in paediatrics. Error rates from 8.4 to $28.2 \%$ have been reported $[2,3]$. Incorrect dosing is thought to be the consequence of the complexity of paediatric prescribing, as dose recommendations based on the child's age, weight or body surface area (BSA) vary for nearly all drugs. Subsequently, multiple calculation steps are required to correctly calculate the dosage [4], and clear dosing guidance is lacking for many drugs that are used off-label in the paediatric population [1, 5-7]. Furthermore, drugs are often diluted and manipulated to meet the need for small doses. Considering all this, the risk of dosing errors in this setting is relatively high. Studies of Rowe et al. and Glover and Sussmane confirm that healthcare professionals have difficulties calculating the correct dose $[8,9]$. 
Computerized dose calculation is considered promising to address paediatric dosing errors $[10,11]$. In a prospective study in a paediatric unit offering computer-calculated dosing for two drugs (i.e. paracetamol and promethazine), computer-calculated dosing significantly reduced the error rate compared with traditional calculation (12.6\% vs. $28.2 \%)$ [3]. Despite its benefits, however, implementation of computercalculated dosing in the paediatric setting has been delayed because computable, explicit and unambiguous paediatric dosing guidelines are currently lacking [12-14].

The Dutch Paediatric Formulary is a fully web-based, free-of-charge, unrestricted platform that provides dosing guidelines on more than 750 drugs, based on best available scientific evidence from registration data, published scientific research, clinical experience and consensus [15, 16]. The work was funded by the Netherlands government and was conducted by the multidisciplinary editorial board composed of paediatric physicians, pharmacists, clinical pharmacologists and other specialists (i.e. neurologists, psychiatrists). The formulary is used by more than 9000 healthcare professionals each day, with over 2 million page views each year. Currently, the Dutch Paediatric Formulary is the gold standard for drug therapy in the Netherlands. German, Austrian and Norwegian versions are under construction.

The availability of digitized paediatric dosing guidelines in the Dutch Paediatric Formulary permitted the development of a website-integrated paediatric dosing calculator. In this paper, we describe the development and implementation of a web-based paediatric dosing calculator embedded in the Dutch Paediatric Formulary platform.

\section{Development of the paediatric dosing calculator}

\section{Key features}

- Based on evidence-based dosing guidelines The Dutch Paediatric Formulary consists of a structured database containing dosing recommendations for children, accessible through an open-access website [15]. Evidencebased dosing recommendations are mostly provided in $\mathrm{mg} / \mathrm{kg} /$ day dosages, which may differ for different age groups. The patient's date of birth is required as an input for the calculator to select the appropriate $\mathrm{mg} / \mathrm{kg} / \mathrm{day}$ dosages.

- In conformity with international standards The dosing calculator was technically designed in conformity with the European Directive on Medical Devices [17] and international standards. These international standards describe the requirements for the development and maintenance of medical software [18], risk management in relation to medical devices [19] and the application of usability engineering to medical devices [20].

\section{Development plan}

The dosing calculator was developed in three phases (Fig. 1). The key steps in the development and risk management of medical applications like a dosing calculator are the predefined description of how the application should be used ('the intended use') and the specification of what the calculator should and should not be able to do (the 'primary operating functions'). The intended use and primary operating functions have been established in collaboration with the editorial board of the Dutch Paediatric Formulary. The primary operating functions were translated to initial functional requirements by assessing and addressing the potential risks. Compliance of the application with the functional requirements was tested by using the calculator for dosing calculations and identifying reasons for failure.

In each phase of development, failures were corrected by corrective and preventive actions (CAPA). The development of the calculator was further driven through a test-retest cycle, which was repeated within the three stages of software development as shown in Fig. 1. The initial software development of the dosing calculator (i.e. the alpha version) was tested internally, while the second version of the dosing calculator (i.e. beta version) was tested externally before releasing the final version.

The selected programming language for building the calculator was Ruby, which has a well-structured code that can easily be used at multiple occasions known as the "convention over configuration' principle. This decreases the number of decisions a programmer has to make and eliminates the complexity of configuration.

\section{Intended use of the calculator}

The paediatric dosing calculator helps healthcare professionals to calculate a drug dose using the dosing information from the Dutch Paediatric Formulary. Intended users of this calculator include those who are Dutch speaking, paediatric healthcare professionals licensed and trained in prescribing, dispensing and administrating drugs to children. The device does not select the preferred drug for a condition; this is left to the discretion of the competent user, supported by existing treatment guidelines. The calculator will be used by a healthcare professional many times during the day for calculating doses for different drugs for different patients. The calculator can be accessed from all computerized devices (i.e. desktops, laptops, smartphones) in different settings (inpatient, out-patient, consulting room, hospital ward, operating theatre, home visits). 


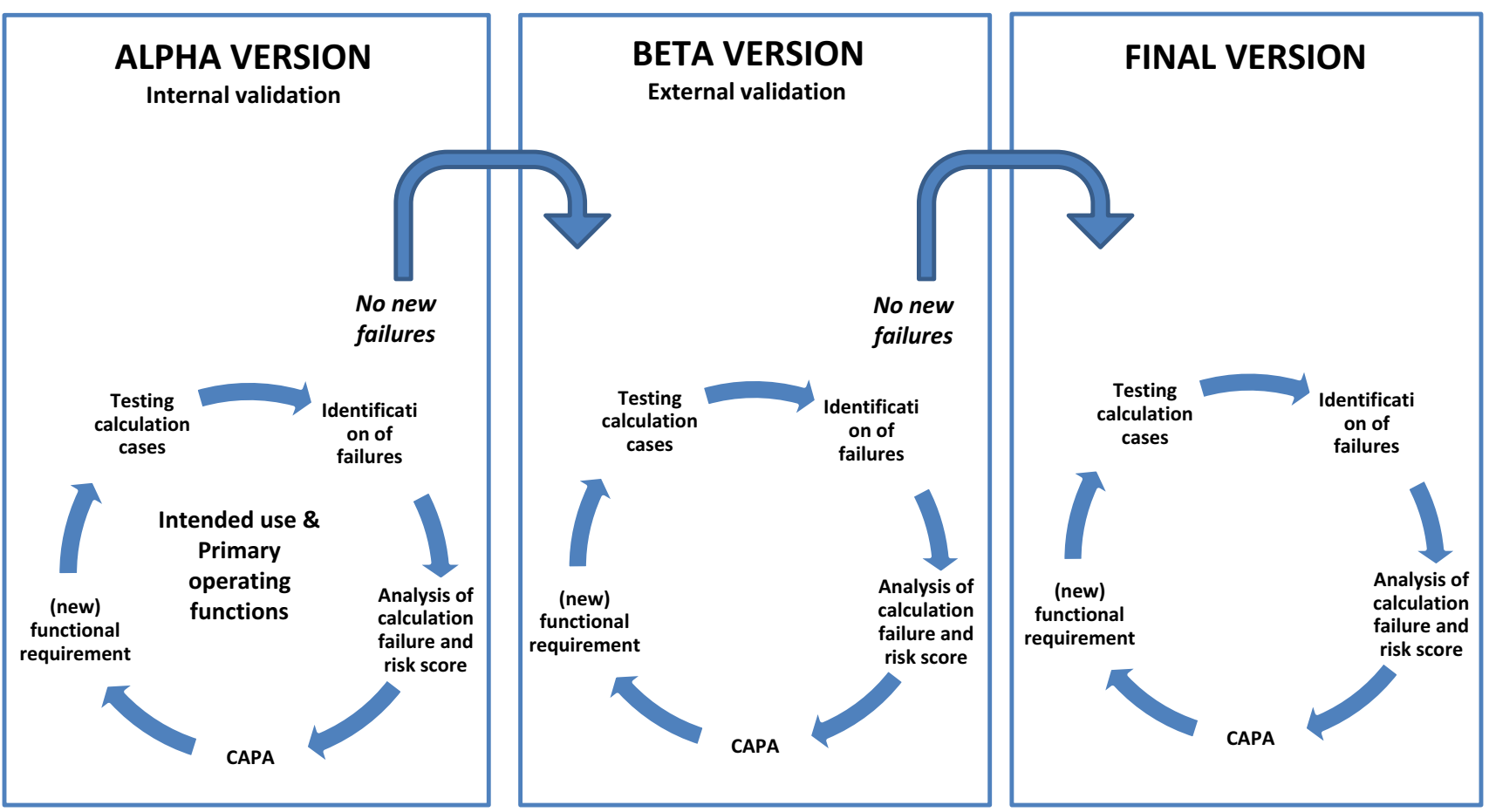

Fig. 1 Representation of the test-retest development cycle. CAPA corrective and preventive actions

\section{How is the calculator supposed to work? ("Primary operating functions")}

The calculator is able to:

- Select the correct age group based on entry of date of birth (day/month/year) and/or bodyweight (g or kg)

- Calculate a dose or a dosing range, including differentiation between a starting dose and maintenance dose; can provide fixed dosing recommendation when appropriate

- Calculate a dose based on bodyweight (g or kg) or BSA $\left(\mathrm{m}^{2}\right)$

- Use different dosing units (e.g. $\mu \mathrm{g} \mathrm{s}, \mathrm{mg}, \mathrm{g}, \mathrm{mL}, \mathrm{IU})$ or dosing frequencies (e.g. daily dosing, divided doses, adjusted dosing per $36 \mathrm{~h}$ or weekly)

- Cross-check maximum dose using different dosing units (mg/day, g/day, IU/day, mg/dose, g/dose, mg/kg/ day, $\mathrm{mg} / \mathrm{m}^{2} /$ day, etc.)

- Round doses

- Convert a calculated dose in micrograms, milligrams or grams to millilitres if concentration of liquid drug is provided by the user

- Summarize all parameters used for the individual calculation in an outcome report

- Switch off and discard all entered values after $10 \mathrm{~min}$ of inactivity
The calculator is not intended for use in patients aged $\geq 18$ years and is not connected to an electronic prescribing system.

The dosing calculator calculates the individual dose for a selected drug based on individual patient characteristics and the drug monograph available in the Dutch Paediatric Formulary. This is a step-by-step process where the device requires the user to enter patient variables and drug variables of the selected drug (Table 1).

The calculator operates correctly on relevant web browsers (Chrome, Internet Explorer, 9.0 and higher, Safari, Firefox, Edge, Opera) and technical platforms (desktop, laptop, mobile devices). Users of the calculator should have access to the terms and conditions for use at all times. Calculations are kept for 3 months in the logging trail on the formularies server to retrieve any potential dosing errors caused by the calculator. Outcome of calculation, date of calculation, drug, date of birth and weight are logged. These data enable the retrieval of dosing errors without patient identification. 
Table 1 Subsequent steps of the dosing calculator: required patient and drug variables for dose calculation

\begin{tabular}{|c|c|c|}
\hline Drug variables & Units & Reasons for use \\
\hline \multicolumn{3}{|c|}{ Step 1: entry of patient variables } \\
\hline Date of birth & Day/month/year & $\begin{array}{l}\text { To enable automatic selection of correct age-based } \\
\text { dosing category }\end{array}$ \\
\hline Weight & $\mathrm{g}$ or $\mathrm{kg}$ & To calculate weight-based doses \\
\hline Height & $\mathrm{cm}$ & $\begin{array}{l}\text { If indicated, to calculate the body surface area } \\
\text { based on weight and height }\end{array}$ \\
\hline Prematurity & Postmenstrual age in weeks & $\begin{array}{l}\text { If postnatal age is less than } 3 \text { months: to be able to } \\
\text { select dosing categories based on gestational } \\
\text { age or postmenstrual age }\end{array}$ \\
\hline \multicolumn{3}{|c|}{ Step 2: selection of drug variables from database } \\
\hline Indication for use & Dropdown list & $\begin{array}{l}\text { Different indications may have different dosing } \\
\text { recommendations; active selection of the right } \\
\text { indication is imperative }\end{array}$ \\
\hline RoA & Dropdown list & $\begin{array}{l}\text { Different RoAs may have different dosing recom- } \\
\text { mendations; active selection of the right RoA is } \\
\text { imperative }\end{array}$ \\
\hline Dosing frequency & Numeric & $\begin{array}{l}\text { If a range of dosing frequencies is provided, the } \\
\text { required dosing frequency should be selected to } \\
\text { enable the calculation of a single dose from the } \\
\text { daily dose }\end{array}$ \\
\hline Value from a dosing range & Numeric & $\begin{array}{l}\text { If a dosing range is provided, the required dosing } \\
\text { value should be selected to enable the calculation }\end{array}$ \\
\hline \multicolumn{3}{|c|}{ Step 3: calculated dose is presented } \\
\hline \multicolumn{3}{|c|}{ Step 4: conversion of calculated dose to $\mathrm{mL}$ (optional) } \\
\hline Concentration of formulation & $\mu \mathrm{g} / \mathrm{mL}, \mathrm{mg} / \mathrm{mL}, \mathrm{g} / \mathrm{mL}, \mathrm{IU} / \mathrm{mL}$, etc & $\begin{array}{l}\text { To convert the dose that is presented in a weight- } \\
\text { based unit to a volume-based unit }\end{array}$ \\
\hline
\end{tabular}

RoA route of administration

\section{Risk management}

\section{Identification of failures and actions to minimize potential harm}

In the initial stage of software development, the project team tested and retested the calculator by calculating doses for randomly selected drugs. Different calculation scenarios (e.g. different dosing units, age groups, weight, routes of administration) and different challenges (respecting the maximum dose, initial and maintenance dose, dose titration) were tested. All calculations made by the dosing calculator were verified with a manual calculator. Any erroneous calculation outcome was defined as a failure of the calculator.

For each identified failure of the calculator, its risk was evaluated [19] on the basis of three criteria:

- Severity, defined as the possibility of the failure to result in harm to the patient

- Frequency of occurrence, defined as how often the failure is expected to occur if no mitigation actions are installed

- Likelihood of detection of failure, defined as whether or not the failure is likely to be detected if no mitigation actions are installed

\section{Table 2 Risk priority score}

\begin{tabular}{|llll}
\hline Score & Severity & Frequency of occurrence & Likelihood of detection \\
\hline 1 & No harm to patient & Rare (less than once a month) & Will be detected \\
\hline 2 & Minimal harm to patient & Often (weekly) & Likely to be detected \\
\hline 3 & Serious harm to patient & Daily & No mode for detection
\end{tabular}


All criteria were scored on a 1-3 scale, resulting in a risk priority score (Table 2).

$$
\begin{aligned}
\text { Risk priority score }= & (\text { severity }) \times(\text { frequency of occurrence }) \\
& \times(\text { likelihood of detection })
\end{aligned}
$$

If the total score was $\geq 9$, CAPA should be implemented to lower the risk. After CAPA, the residual risk score should be reduced to $\leq 3$. A total risk priority score of 4-9 was acceptable if the severity equalled 1 (i.e. no harm to the patient).

The identified failures and risks were translated to CAPA [21] and to new functional requirements needed to mitigate the identified risks. CAPA were aimed at either reducing the seriousness of harm to the patients, at reducing the occurrence or at improving strategies for detection of the failure. The new functional requirements re-entered the test cycle until no new failures were identified (Fig. 1). Table 3 presents selected failures from the risk analysis table (E-supplement 1: Complete risk analysis table; see the electronic supplementary material, online resource 1) as examples for addressing failures and instalment of CAPA.

\section{Validation of the calculator}

The generated alpha version was further systematically validated by performing two calculations for 230 drugs from the formulary for an infant (10 kg, $75 \mathrm{~cm}, 1$ year of age) and an adolescent ( $50 \mathrm{~kg}, 162 \mathrm{~cm}, 13$ years of age). For every fifth drug of the formulary based on alphabetical order and every fifth drug of the formulary based on the Anatomical Therapeutic Chemical (ATC) Classification System [22], the two calculations were performed for the first indication listed in the formulary. If a range was presented, the lowest dose and lowest frequency were selected.

The calculations performed by the alpha version still contained a calculation error in 27 cases out of 460 calculations (6\%), as was verified by manual calculation for each calculation. In 13 of these cases, this concerned a suboptimal presentation of the titration of drugs from a starting dose to a maintenance dose range; in four cases, it concerned a missing calculation; in three cases, it concerned a missing presentation of frequency of administration; and in seven cases, it concerned an erroneous calculation. Before converting to the beta version, these failures were again identified, analyzed, resolved and tested again, until no new errors occurred.

\section{Implementation}

After securing flawless performance of the alpha version, the beta version was launched for use by healthcare professionals on September 7, 2015. The beta version is the second version of the dosing calculator, in which the calculation errors encountered with the alpha version have been resolved. However, users were instructed to use the beta version with due caution as this version might still cause some errors. Whenever possible, users were encouraged to report a problem or suspected malfunction of the calculator by completing a semi-automated digital form, which was included in each step of the calculator. This form automatically saves the parameters entered. All reports are reviewed by the project manager, and if needed, malfunctions are reproduced to analyse the problem. An identified failure would be added to the risk analysis table and evaluated for severity, frequency of occurrence and likelihood of detection, resulting in new functional requirements to correct failure and testing of the corrective action. Users were prompted to agree to these conditions for use of the beta version. In 16 months, this beta version was used approximately 80,000 times.

Users reported 41 cases of suspected malfunctioning of the calculator. Two of these cases concerned a serious malfunction (Table 4). The remaining cases concerned suboptimal usability (print feature, obstruction of data entry by autocomplete function of Samsung galaxy devices and comments on the digital reporting form), and perceived errors (reports on calculator not providing a calculation for patients of ages for which no dosing recommendations are listed in the formulary).

On June 30, 2017, the beta version was converted to the final version. The final version of the dosing calculator comprises five steps (Table 1 and E-supplement 2):

- Step 1: enter patient variables

- Step 2: enter the selection of drug variables

- Step 3: display the calculated dose for the selected age/ age range

- Step 4: provide the option to convert the calculated dose to millilitres

- Step 5: give a summary of patient and drug variables used to perform the calculation

The performance of the final version of the calculator is still continuously monitored by analysing user-reported problems reported via the semi-automated form. From July 2017 to June 2019, eight reports of suspected malfunction were submitted. Three of these malfunctions required correction.

\section{Conformité Européenne marking}

Medical applications like the calculator qualify as a medical device according to EU legislation [17]. Different certification requirements are applicable based on the risk classification of the device. The risk of the dosing calculator 
Table 3 Selection of identified failures during the development process (full-table in E-Supplement 1)

\begin{tabular}{|c|c|c|c|}
\hline Failure & Risk priority score ${ }^{\mathrm{a}}$ & Corrective and preventive actions & $\begin{array}{l}\text { Residual risk } \\
\text { score }^{\mathrm{a}}\end{array}$ \\
\hline $\begin{array}{l}\text { Incorrect entry of weight may lead to } \\
\text { incorrect calculated dose }\end{array}$ & $3 \times 3 \times 2=18$ & $\begin{array}{l}\text { The weight is entered in kg and calculator selects age group } \\
\text { based on weight if indicated. The system checks weight } \\
\text { against age for normal growth of children in the Netherlands } \\
\text { If a deviation ( }>2 \text { standard deviations from normal) occurs, the } \\
\text { system alarms the user, and user must confirm that date of } \\
\text { birth and weight are correct or change the input } \\
\text { A summary of the entered data of the user, or auto-selected } \\
\text { by the calculator, is visible at all times on the right side and } \\
\text { always has the same setup }\end{array}$ & $3 \times 1 \times 1=3$ \\
\hline $\begin{array}{l}\text { Wrong selection of indication from a } \\
\text { dropdown list may lead to incorrect } \\
\text { calculated dose (based on a different } \\
\text { indication) }\end{array}$ & $2 \times 2 \times 3=12$ & $\begin{array}{l}\text { An empty line is shown in dropdown boxes to mandate an } \\
\text { active selection; if mandatory selection is not completed, } \\
\text { the calculator will alert the user that required information is } \\
\text { missing } \\
\text { Only those indications/ROAs/frequencies that apply to age and } \\
\text { weight of patient are presented; if the choice is limited to one } \\
\text { option, selection is made automatically } \\
\text { A summary of the entered data of the user, or auto-selected } \\
\text { by the calculator, is visible at all times; the summary can be } \\
\text { printed for verification purposes }\end{array}$ & $2 \times 1 \times 1=2$ \\
\hline $\begin{array}{l}\text { If the calculated dose exceeds the } \\
\text { maximum dose, this may lead to } \\
\text { overdosing the patient }\end{array}$ & $3 \times 3 \times 3=27$ & $\begin{array}{l}\text { Calculator cross-checks calculated dose for maximum dose; if } \\
\text { calculated dose exceeds maximum dose, the maximum dose } \\
\text { is presented as recommended dose }\end{array}$ & $1 \times 1 \times 1=1$ \\
\hline $\begin{array}{l}\text { Calculating a dose for an adult using } \\
\text { this calculator could lead to an inad- } \\
\text { equate drug dosage for an adult }\end{array}$ & $3 \times 1 \times 3=9$ & $\begin{array}{l}\text { Cross-check on date of birth; if the calculated age is }>18 \text { years, } \\
\text { the user should be referred to other dosing guidelines and no } \\
\text { calculated dose is provided }\end{array}$ & $1 \times 1 \times 1=1$ \\
\hline $\begin{array}{l}\text { Drug-related ( }>1 \text { active substance, } \\
\text { complex titration regimens) or } \\
\text { patient-related (speed of physiologi- } \\
\text { cal maturation of premature born } \\
\text { neonates) aspects prohibit the safe } \\
\text { use of the calculator }\end{array}$ & $3 \times 3 \times 2=18$ & $\begin{array}{l}\text { For certain drugs, the calculator cannot be used safely } \\
\text { For these situations, the calculator is switched off for single } \\
\text { indications or drugs; a clarification to the user is provided } \\
\text { when the calculator cannot be used }\end{array}$ & $1 \times 1 \times 1=1$ \\
\hline $\begin{array}{l}\text { User is confused by presentation and/ } \\
\text { or interpretation of calculated dose }\end{array}$ & $3 \times 3 \times 3=27$ & $\begin{array}{l}\text { Applying human factors and usability engineering to optimize } \\
\text { medical device design } \\
\text { The dosage results are marked in a green-lined box. The format } \\
\text { for showing the result is ROA, calculated single dose, fre- } \\
\text { quency of dosing and daily dose }\end{array}$ & $3 \times 1 \times 1=3$ \\
\hline $\begin{array}{l}\text { Calculated dose shows too many } \\
\text { decimals (trailing zeros), leading to } \\
\text { incorrect interpretation of calculated } \\
\text { dose }\end{array}$ & $3 \times 2 \times 3=18$ & $\begin{array}{l}\text { Points are used for thousands and commas are used for deci- } \\
\text { mals; ' } 1000 \text { ' is shown as ' } 1 \text { ' and ' } 0.10 \text { ' is shown as ' } 0.1 \text { ' }\end{array}$ & $1 \times 1 \times 3=3$ \\
\hline
\end{tabular}

$R O A$ route of administration

${ }^{\text {a }}$ Severity $\times$ frequency of occurrence $\times$ likelihood of detection $=$ score

was classified based on criteria set by the Dutch Center of Expertise on E-Health NICTIZ [23].

Following the blue arrows in the NICTIZ flowchart of Fig. 2, action B for certification by the manufacturer applies. For the purpose of certification, the development of the calculator and the risk management plan, containing all identified failures and installed corrective actions of the dosing calculator, were described in the technical file. This technical file was submitted to the Dutch competent authority Farmatec/CIBG, which registered the calculator for Conformité Européenne (CE) marking as a risk class 'A' medical device as of May 17, 2017. CE marking is a certification mark that indicates conformity with health, safety, and environmental protection standards for products sold within the European Economic Area.

\section{Limitations of use}

During the development process, we encountered a number of problems, which forced us to exclude some specific populations and drugs from using the calculator. 
Table 4 Identified failures and risks of the beta version, including installed corrective and preventive actions

\begin{tabular}{|c|c|c|c|c|}
\hline Failure & Risk & Risk priority score ${ }^{\mathrm{a}}$ & $\begin{array}{l}\text { Corrective and preventive } \\
\text { actions }\end{array}$ & Residual risk score \\
\hline $\begin{array}{l}\text { Calculation error due to differ- } \\
\text { ent dosing units for concen- } \\
\text { tration and dosing }\end{array}$ & $\begin{array}{l}\text { Wrong entry of concentration } \\
\text { leads to administration of } \\
\text { wrong dose }\end{array}$ & $3 \times 3 \times 3=27$ & $\begin{array}{l}\text { The selected concentration for } \\
\text { calculation is included in the } \\
\text { summary } \\
\text { The entry of units of the liquid } \\
\text { concentration is cross-checked } \\
\text { with the dosing unit; the } \\
\text { calculation will only show if } \\
\text { the units are in line with the } \\
\text { dosing unit } \\
\text { Print of summary }\end{array}$ & $3 \times 1 \times 1=3$ \\
\hline $\begin{array}{l}\text { Ambiguous data representa- } \\
\text { tion; if calculated dose } \\
\text { exceeds the maximum dose, } \\
\text { the calculated dose is shown } \\
\text { in addition to the maximum } \\
\text { dose }\end{array}$ & $\begin{array}{l}\text { Use of calculated dose instead } \\
\text { of maximum dose }\end{array}$ & $3 \times 3 \times 2=18$ & $\begin{array}{l}\text { The calculated dose that exceeds } \\
\text { the maximum dose is deleted } \\
\text { from the calculation results }\end{array}$ & $1 \times 1 \times 1=1$ \\
\hline
\end{tabular}

${ }^{\text {a }}$ Severity $\times$ frequency of occurrence $\times$ likelihood of detection $=$ score

\section{Use in premature neonates}

Although the calculator is technically able to calculate a dose for a premature born neonate, most dose recommendations provided by the Dutch Paediatric Formulary describe an initial dose for premature neonates that were born at a certain postmenstrual age (PMA), birth weight or postnatal age, but do not describe when to adjust the dose with increasing postnatal age and maturation. A neonate born at 28 weeks gestational age with a postnatal age of 4 weeks (PMA of 32 weeks) is not the same as a 2-day-old neonate born at 32 weeks gestational age (likewise a PMA of 32 weeks). Therefore, we decided to inactivate the calculator for those drugs where scientific information on dose adjustment based on postnatal maturation in premature neonates after birth is lacking.

\section{Drugs compounded by multiple active ingredients}

The dose calculation for a drug with two or more active ingredients (i.e. trimethoprim-sulfamethoxazole or amoxicillin-clavulanic acid) was at first programmed by defining the dose recommendation as the sum of both ingredients: $36 \mathrm{mg} / \mathrm{kg} /$ day for sulfamethoxazole/trimethoprim, referring to $30 \mathrm{mg}$ sulfamethoxazole and $6 \mathrm{mg}$ trimethoprim. This worked adequately well for drugs with a similar ratio for both active drugs in all available formulations. Amoxicillin-clavulanic acid formulations, however, comprise different ratios of active ingredients, thereby compromising this approach. Furthermore, users reported unfamiliarity with the summed doses compared with a separated dose for both active ingredients. Therefore, we decided to inactivate the calculator for drug formulations with combined active ingredients.

\section{Complex titration}

The calculator can manage calculations for an initial and a maintenance dose simultaneously. Stepwise titration upon efficacy and toxicity can be calculated. However, when dosing recommendations are compiled by complex titration regimes containing unequal dose increments or intervals, the calculator cannot be used (e.g. salbutamol intravenous in acute asthma: starting dose $0.1 \mu \mathrm{g} / \mathrm{kg} / \mathrm{min}$ continuous infusion, increase starting dose upon clinical symptoms, tachycardia and arterial blood gases to $0.1 \mu \mathrm{g} / \mathrm{kg} / \mathrm{min}$ per dose increment $0.1-0.5 \mu \mathrm{g} / \mathrm{kg} / \mathrm{min}$; to $0.2 \mu \mathrm{g} / \mathrm{kg} / \mathrm{min}$ per dose increment $0.5-1.0 \mu \mathrm{g} / \mathrm{kg} / \mathrm{min}$ and $0.5 \mu \mathrm{g} / \mathrm{kg} / \mathrm{min}$ per dose increment when dosing within the range of $1.0-10 \mu \mathrm{g}$ $/ \mathrm{kg} / \mathrm{min})$.

\section{Discussion}

Our work presents the successful development and implementation of a web-based paediatric dosing calculator integrated into the Dutch Paediatric Formulary. It provides a deeper understanding of the technical requirements, human factors engineering and risk-minimization measures (CAPA) required to ensure the validity of the calculations and safe use of the calculator by healthcare professionals.

Most dosing calculators, such as Medscape Weight Based Divided Dose Calculator [24] and Omnicalculator [25], are simple web-based calculation tools that calculate a 


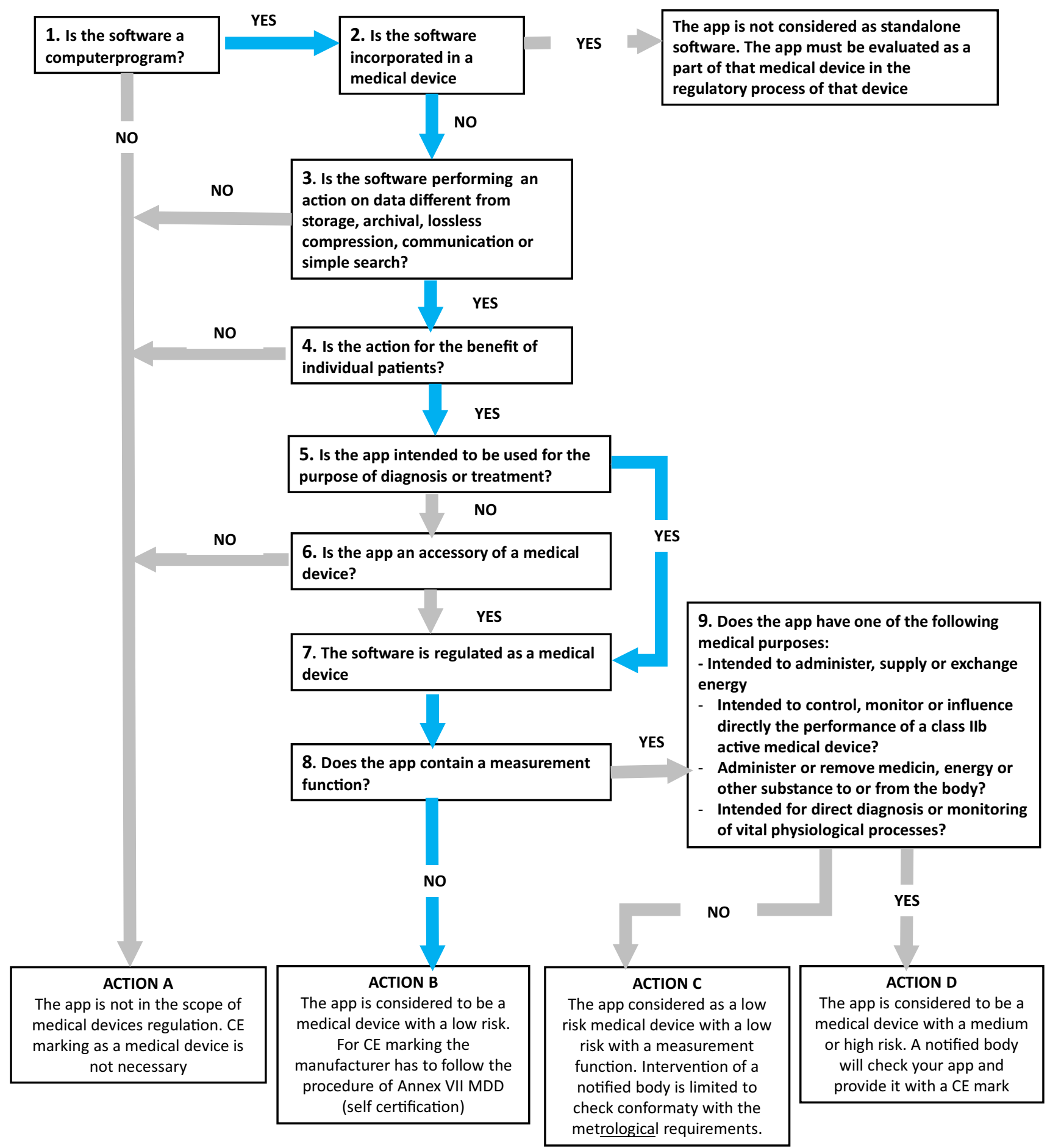

Fig. 2 Classification of medical device based on NICTIZ criteria

weight-based dose just like a manual calculator, providing a single dose recommendation. The simplicity of these calculators is an advantage, but they do not detect typing errors, prevent excess of the maximum dose or verify the correctness of the recommended dose. In addition, the data for dosing recommendation have to be extracted from other sources. Of note, the Medscape calculator should be used for educational purposes only, not for the diagnosis or treatment of any health 
problem or disease. Other available dosing calculators, such as the PEDeDose calculator [26] or various emergency drug dosing calculators $[27,28]$ integrate dosages and provide a range of dosage recommendations, but it is unclear how the underlying doses were selected and how these calculator tools have been developed/validated. Moreover, emergency drug dosing calculators only support dose calculations of relatively few drugs. Alternatively, healthcare professionals use Excel spreadsheets to calculate paediatric doses, but these spreadsheets are prone to unintended modifications [29].

Calculation errors resulting from the use of a dosing calculator are assumed to be driven by software programming errors. The failures identified during the development and the evaluation of our web-based paediatric dosing calculator in a separate simulation study [30] indicate, however, that a correctly calculated dose for an individual patient is equally dependent on correct data entry, selection of parameters and interpretation of data by the user. Users' skills of interacting with technology need to be taken into account when developing healthcare technology solutions [29].

Many of the failures related to erroneous selection of parameters and incorrect entry of data are corrected by measures that increase the likelihood of detection. Therefore, cross-checking and verification of the calculated dose by a second healthcare professional before dispensing to a patient is still required. The calculator cannot replace these important checks. Furthermore, the transcription of the dose as calculated by the calculator to a prescribing system is prone to error. Some of the errors caused by incorrect data entry, selection or transcription of parameters may be prevented by incorporation of the calculator into computerized provider order entry (CPOE) systems.

We initially intended to apply the calculator to all drugs, all age groups and all dosing recommendations provided in the formulary. However, some calculation scenarios, as described in the 'Limitations of use' section, required major adaptations to the formulary database, additional scripts or adjustment of dosing content to enable these calculations. Some of these issues could have been overcome by stratifying for the different strengths of the formulations or listing multiple titration steps. However, we decided to discard calculations for neonates in selected cases, combined drugs and complex titration regimens as including these scenarios would have compromised the simplicity and clarity of dosing recommendations on the formulary's website and would have increased the number of interpretation errors. In addition, these adaptations would have required a disproportionate use of resources, considering the limited number of drugs to which these alternative calculation scenarios apply. The incompleteness of neonatal dosing information is now being addressed by a separate project (the Dutch Paediatric Formulary NEODOSE project).

Unlike many other digitally available medical calculator tools [24-28], our calculator was developed in conformity with requirements of the EU Medical Devices Directive and has been registered as a medical device by the competent authority of the Netherlands (Farmatec/CIBG). Conformity with applicable directives mandates a structured, stepwise approach that enables identifying failures, adapting the functional requirements and improving human factor design. Systematically addressing every failure in terms of potential harm to the patient, frequency of occurrence and likelihood of detection enforces risk management strategies. Conformity therefore ensures the safety of the calculator, promotes the validity of the device and enhances the transparency of the development process and risk management plan.

Several studies have evaluated the quality of healthcarerelated applications. Loy et al. [31] concluded that the reliability of healthcare-related applications in general is poor. The evaluation in this study included the intended use, reliability, usability and privacy of the apps, but not the technical quality and development or risk management. A study by Morse et al. [32] assessed only the presence of different features, such as a dosing calculator, interaction checker or availability of dose recommendations; in this study, too, the technical specifications and risk management features were not assessed. Findings from a review by Boulos et al. [33] confirmed the need to develop medical apps and devices in conformity with the EU Medical Devices Directive [17].

In conclusion, we successfully developed and implemented a paediatric dosing calculator integrated into the web-based Dutch Paediatric Formulary. The in-depth description of the development and risk management plan may help potential developers to increase the quality of healthcare applications.

\section{Take-home messages}

- While health information technology has been advocated to improve patient safety, the broad implementation of computer-calculated dosing in the paediatric setting is currently lacking

- A paediatric dosing calculator was developed in conformity with requirements of the European Union Medical Devices Directive and international standards

- The developed dosing calculator was internally and externally validated to reduce dosing errors

- This work may be of interest for anyone involved in health technology strategies aimed at decreasing dosing errors and could be used as a blueprint for similar initiatives

Author contributions $\mathrm{TZ}$ coordinated the development of the calculator, tested the calculator and drafted the initial manuscript. TZ, MH and HS contributed to the definition of the intended use and the design of 
the primary operating functions, and were involved in the analysis of failures and the design of CAPA. LG technically designed and developed the calculator. All authors reviewed and revised the manuscript and approved the final manuscript as submitted.

Funding Tjitske van der Zanden is managing director of the Dutch Paediatric Pharmacotherapy Expertise Network. Saskia de Wildt is the medical director of the Dutch Paediatric Pharmacotherapy Expertise Network. Lennard Goedknegt is the director of Health E-Solutions. The other authors have no financial disclosures relevant to this article. The Netherlands Organization for Health Research and Development (ZonMw): Grant (113200951) Paediatric Dosing Module.

\section{Compliance with ethical standards}

Conflict of interest The authors declare they have no other conflicts of interest.

Open Access This article is licensed under a Creative Commons Attribution-NonCommercial 4.0 International License, which permits any non-commercial use, sharing, adaptation, distribution and reproduction in any medium or format, as long as you give appropriate credit to the original author(s) and the source, provide a link to the Creative Commons licence, and indicate if changes were made. The images or other third party material in this article are included in the article's Creative Commons licence, unless indicated otherwise in a credit line to the material. If material is not included in the article's Creative Commons licence and your intended use is not permitted by statutory regulation or exceeds the permitted use, you will need to obtain permission directly from the copyright holder.To view a copy of this licence, visit http://creativecommons.org/licenses/by-nc/4.0/.

\section{References}

1. Kaushal R, Bates DW, Landrigan C, et al. Medication errors and adverse drug events in pediatric inpatients. JAMA. 2001;285(16):2114-200.

2. Davis T, Thoong H, Kelsey A, et al. Categorising paediatric prescribing errors by junior doctors through prescribing competency assessment: does assessment reflect actual practice? Eur J Clin Pharmacol. 2013;69(5):1163-6.

3. Kirk RC, Li-Meng Goh D, Packia J, et al. Computer calculated dose in paediatric prescribing. Drug Saf. 2005;28(9):817-24.

4. Wong IC, Wong LY, Cranswick NE. Minimising medication errors in children. Arch Dis Child. 2009;94(2):161-4.

5. Conroy S, Sweis D, Planner C, et al. Interventions to reduce dosing errors in children: a systematic review of the literature. Drug Saf. 2007;30(12):1111-25.

6. Wong IC, Ghaleb MA, Franklin BD, et al. Incidence and nature of dosing errors in paediatric medications: a systematic review. Drug Saf. 2004;27(9):661-70.

7. Abramson EL, Kaushal R. Computerized provider order entry and patient safety. Pediatr Clin N Am. 2012;59(6):1247-55.

8. Rowe C, Koren T, Koren G. Errors by paediatric residents in calculating drug doses. Arch Dis Child. 1998;79(1):56-8.

9. Glover ML, Sussmane JB. Assessing pediatrics residents' mathematical skills for prescribing medication: a need for improved training. Acad Med. 2002;77(10):1007-100.

10. Doherty C, Mc DC. Tenfold medication errors: 5 years' experience at a university-affiliated pediatric hospital. Pediatrics. 2012;129(5):916-24.
11. Wong I. Ways to reduce drug dose calculation errors in children. J Health Serv Res Policy. 2010;15(Suppl 1):68-70.

12. Ferranti JM, Horvath MM, Jansen J, et al. Using a computerized provider order entry system to meet the unique prescribing needs of children: description of an advanced dosing model. BMC Med Inform Decis Mak. 2011. https://doi. org/10.1186/1472-6947-11-14.

13. Kim GR, Lehmann CU, Council on Clinical Information Technology. Pediatric aspects of inpatient health information technology systems. Pediatrics. 2008;122(6):e1287-e12961296.

14. Lehmann CU, Kim GR, Gujral R, et al. Decreasing errors in pediatric continuous intravenous infusions. Pediatr Crit Care Med. 2006; 7(3):225-30.

15. van der Zanden T, De Wildt S, Liem T, et al. Developing a pediatric formulary for the Netherlands. Arch Dis Child. 2017;102(4):357-61.

16. Nederlands Kenniscentrum voor Farmacotherapie bij Kinderen. Kinderformularium. 2020. www.kinderformularium.nl Accessed 11 Feb 2020.

17. European Economic Council. Directive 93/43/EEC. 1993.

18. International Electrotechnical Commission. IEC 62304: health software-software life cycle processes. 2006.

19. International Organization for Standardization. ISO 14971:2007: medical devices - application of risk management to medical devices. 2007.

20. International Organization for Standardization. IEC 62366: medical devices - application of usability engineering to medical devices. 2007.

21. International Organization for Standardization. ISO 9001/2015: quality Management systems. Geneva Switzerland. 2015.

22. WHO Collaboration Centre for Drug Statistics Methodology. ATC. https://www.whocc.no/atc/structure_and_principles/. Accessed 15 Feb 2018

23. Ekker A, van Rest B. NiCTIZ 13005: whitepaper. Medische apps, is certificeren nodig? 2013.

24. Foundation Internet Services LLC. MedCalc 3000—weight based divided dose calculator. https://ebmcalc.com/pubapps/pediat.htm. Accessed 1 Nov 2019.

25. Bialek Lea. Omnicalculator-dosage calculator. https://www. omnicalculator.com/health/dosage. Accessed 1 Nov 2019.

26. PEDeus A. PEDeDose 2019. https://www.PEDeDose.ch. Accessed 1 Nov 2019.

27. Evelina London Children's Healthcare. Emergency drug dose calculator. 2009. https://www.evelinalondon.nhs.uk/resources/ our-services/hospital/south-thames-retrieval-service/Drug-calcu lators/emergency-drug-calculator.pdf. Accessed 1 Nov 2019.

28. Perth Children's Hospital. Emergency calculator. 2017. https:// kidshealthwa.com/wp-content/uploads/calculators/EmergencyCalculator-v9-2/EmergencyCalculator.htm. Accessed 1 Nov 2019.

29. De Wildt S, Verzijden R, van den Anker J, et al. Information technology cannot guarantee patient safety. BMJ. 2007;334(7598):851-2.

30. Van der Zanden T, de Hoog M, Windster J, et al. Does a dose calculator as an add-on to a web-based pediatric formulary reduce calculation errors in pediatric dosing? A non-randomized controlled study. Pediatr Drugs. 2020. https://doi.org/10.1007/s4027 2-020-00386-3.

31. Loy JS, Ali EE, Yap KY. Quality assessment of medical apps that target medication-related problems. J Manag Care Spec Pharm. 2016;22(10):1124-40.

32. Morse SS, Murugiah MK, Soh YC, et al. Mobile health applications for pediatric care: review and comparison. Ther Innov Regul Sci. 2018;52(3):383-91.

33. Boulos MN, Brewer AC, Karimkhani C, et al. Mobile medical and health apps: state of the art, concerns, regulatory control and certification. Online J Public Health Inform. 2014;5(3):229. 